Análisis de dos tocados de élite localizados en el complejo funerario adjudicado al gobernante «Garra de Jaguar » en Calakmul, Campeche, México

\title{
Renata García-Moreno
}

\section{CpenEdition}

\section{Journals}

Edición electrónica

URL: https://journals.openedition.org/jsa/1579

DOI: $10.4000 /$ jsa. 1579

ISSN: 1957-7842

Editor

Société des américanistes

Edición impresa

Fecha de publicación: 5 junio 2003

Paginación: 207-220

ISSN: 0037-9174

\section{Referencia electrónica}

Renata García-Moreno, «Análisis de dos tocados de élite localizados en el complejo funerario adjudicado al gobernante "Garra de Jaguar » en Calakmul, Campeche, México», Journal de la Société des américanistes [En línea], 89-2 | 2003, Publicado el 05 junio 2008, consultado el 02 septiembre 2022. URL: http://journals.openedition.org/jsa/1579 ; DOl: https://doi.org/10.4000/jsa. 1579 


\title{
ANÁLISIS DE DOS TOCADOS DE ÉLITE LOCALIZADOS EN EL COMPLEJO FUNERARIO ADJUDICADO AL GOBERNANTE « GARRA DE JAGUAR » EN CALAKMUL, CAMPECHE, MÉXICO
}

\author{
Renata GARCÍA-MORENO *
}

\section{EL ESTUDIO DE LA INDUMENTARIA PREHISPANICA}

La indumentaria ha sido utilizada a través del tiempo, más allá de sus fines prácticos, como un indicador social. Los grupos dirigentes generalmente se han distinguido al portar elaborados atuendos y joyas, cuyo valor no sólo radica en la selección de materiales preciados para su fabricación, sino en el uso de emblemas y otros símbolos enfocados a testimoniar supremacía.

En contextos rituales los atuendos adquieren una importancia fundamental. A través de su simbolismo, éstos ayudan al hombre a transformarse, confiriéndole gran parte de las cualidades sobrenaturales requeridas para hacer frente a las fuerzas del universo. Así, la vestimenta y los adornos se combinan con las actitudes y los gestos corporales para evocar las relaciones entre los individuos de una sociedad y su entorno (Arnoldi y Kreamer 1995).

Desde la antigüedad ha existido la asignación de valores metafóricos a las prendas con respecto a su posición en el cuerpo humano. Así como los artefactos asociados a las manos pueden indicar implementos de acción, las prendas asociadas a la cabeza adquieren, junto con ella, una posición sobresaliente y esencial. Integrándose al rostro, éstas contribuyen a portar valores de identidad, ya sea a nivel individual o colectivo. Así, dichas prendas resultan indispensables en ciertas actividades públicas y ceremoniales, atestiguando la pertenencia a un grupo social e incluso validando la posesión de poder y sacralidad de una persona (Schele y Miller 1992 ; Houston y Stuart 1998).

En la cultura maya el reflejo de la estratificación social es evidente en la indumentaria. A través de sus pinturas y esculturas se percibe la variedad de atuendos de la época, particularmente en lo que respecta a los elementos que decoran las cabezas. Estos van desde simples atados y diademas hasta los más complejos turbantes y tocados. Sin embargo, la escasez de hallazgos arqueológicos de este tipo de objetos ha limitado su estudio material específico. Lo anterior se debe en gran medida a la utilización de materiales orgánicos para su elabora-

* Université de Paris I, Centre de recherche et de restauration des musées de France C2RMF, Site Carrousel. 6, rue des Pyramides 75041 Paris Cedex 01 [renata.garcia-moreno@culture.gouv.fr].

Journal de la Société des Américanistes, 2003, 89-2, pp. 207-220. CSociété des Américanistes. 
ción. En la mayoría de los casos, éstos se desintegran rápidamente después de su enterramiento o abandono. En los excepcionales casos donde se conservan sus vestigios, su identificación durante las excavaciones puede dificultarse por la pérdida de su coherencia formal. Asimismo, la falta de un valor estético puede generar el desinterés en esta clase de materiales, menospreciando su potencial como sujeto de investigación antropológica.

La rareza de este tipo de hallazgos obligó a que el acercamiento a la vestimenta prehispánica se llevara a cabo principalmente a través de las representaciones en el arte, las fuentes históricas y la información etnográfica. La falta de documentos de la época prehispánica y el desfase cronológico, tanto de los escritos de cronistas como de los estudios etnográficos con respecto a la indumentaria prehispánica, representan obstáculos para este género de estudios. El dinamismo inherente de las sociedades hace que las características tecnológicas, estéticas y/o conceptuales de los atavíos sean vulnerables al paso del tiempo. Estas repercusiones, ampliadas en nuestro caso por el devenir histórico de Mesoamérica a través de la Conquista y la Colonia, pueden constatarse en importantes variantes y modificaciones. Las diferencias no sólo radican en la forma misma de las prendas, sino en la selección de los materiales, los procesos de fabricación, el colorido y la iconografía entre otros aspectos (Anawalt 1990).

A estas dificultades se suma la problemática del estudio de la vestimenta a través de las representaciones en pintura y escultura, donde sobresalen las confusiones suscitadas como resultado de las soluciones plásticas de cada artista. En efecto, en el área maya el estilo y los procesos de abstracción al pintar o esculpir un elemento, pueden dificultar la identificación de las prendas y de sus volúmenes reales, así como de los materiales con los que pudieron haber sido elaboradas. No obstante la permanencia de algunas características y de ciertos motivos iconográficos, nuestro conocimiento de la vestimenta mesoamericana resulta fragmentario con respecto a los períodos más tempranos, siendo la evidencia arqueológica insustituible para obtener datos materiales concretos (Spinden 1913 ; Proskouriakoff 1950 ; Anawalt 1990 ; Schele y Miller 1992; Tate 1992).

\section{LOS TOCADOS EN EL CONTEXTO ARQUEOLÓGICO}

Las tumbas 4 y 6 de la subestructura II-B de Calakmul (Figura 1) forman parte de un mismo complejo funerario, adjudicado, por el contexto epigráfico y su datación, al gobernante Yuknom Yich' ak' K'ak o « Garra de Jaguar ». Este recinto se compone de dos cámaras contiguas : la principal (tumba 4) contenía los restos del dignatario, cuya muerte se fecharía en el 702 d.C., mientras que en la cámara anexa (tumba 6) fueron sepultados una mujer adulta y un niño, el cual yacía entre sus piernas. Estos adultos presentaban suntuosas ofrendas. Asi- 
mismo, alrededor del cráneo de ambos personajes se localizaron restos de un material gris muy degradado, de aspecto fibroso y poco denso (Figuras 2 y 3). En la tumba 6 el tocado fue identificado sin mayor problema ya que, a pesar de las numerosas fragmentaciones, su forma y volumen se habían conservado (Figura 3a). En el caso del dignatario, el material fibroso estaba claramente asociado a teselas de piedra verde y concha y a escamas de estuco polícromo (Figuras 2a y b). Era evidente que se trataba de un solo objeto y que la superposición aleatoria de los fragmentos había sido ocasionada por su paulatina descomposición. La alta complejidad formal y el deterioro de este tocado dificultaban el estudio de su forma original. La excavación minuciosa de estos objetos implicó una planificación particular con el fin de recabar la mayor cantidad posible de información y de conservar sus vestigios (Carrasco et al. 1999).

Cada grupo de mosaico fue registrado detalladamente en escala real. Las fibras y los restos de estuco polícromo fueron muestreados para su posterior identificación química previamente a los tratamientos de conservación que pudieran afectar sus resultados. Algunas pastas del mosaico presentaban improntas de fibras y huellas de teselas. El volumen y la forma de algunos fragmentos de mosaico se habían conservado, por lo que durante la excavación fue prioritario mantener la asociación directa entre los materiales. Después de su consolidación y velado, fue posible extraer los grupos, conservando su unidad (García-Moreno y Granados 2000).

Cabe señalar que en otros sitios del Petén se han hallado restos similares, como en el entierro 30 de Dos Pilas, en las tumbas 196 de Tikal, 19 y 23 de Rio Azul. En estos casos se reporta la presencia de restos de material esponjoso, posiblemente orgánico, asociado en algunos casos a teselas de jadeita y/o concha alrededor de los cráneos de los personajes inhumados (Demarest et al. 1991 ; Helmuth 1967 ; Hall 1989).

\section{EL ESTUDIO FORMAL}

El estudio formal se llevó a cabo mediante el mismo método utilizado para la restauración de la vestimenta. Cada fragmento de mosaico fue colocado sobre placas de acrílico transparente, con base en las coordenadas en las que había sido hallado. La superposición de las placas, simulando los niveles de excavación, permitió ver la continuidad entre los grupos de mosaico y precisar la posición de los elementos iconográficos del tocado (García-Moreno y Granados 1999; 2000).

Resulta indispensable aclarar que la integridad del tocado nunca podrá ser recuperada de manera objetiva. El reintegrar lagunas para completar su forma nos obligaría a incurrir en una reconstrucción hipotética. Por consiguiente, se ha preferido programar una futura restauración de los elementos aislados, 


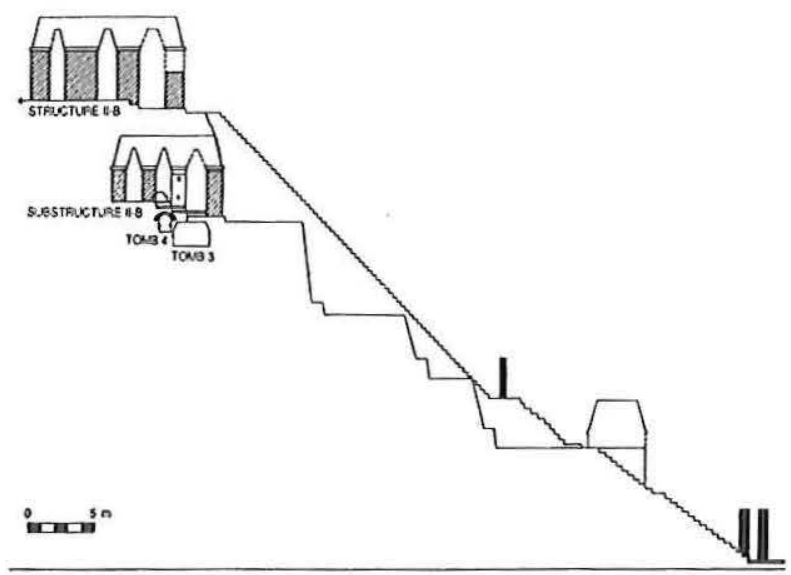

FIG. 1 - Corte de la subestructura II-B, donde se localiza la umba de « Garra de Jaguar »
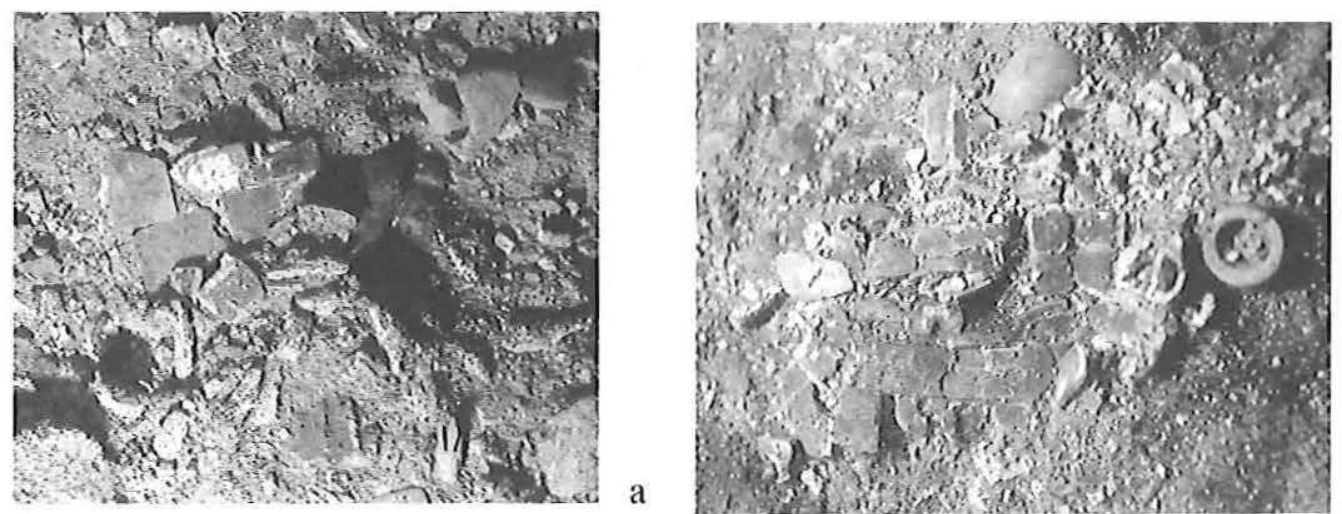

b

Fig. 2 - Vestigios del tocado de la tumba 4 in situ, donde se observan los unguinales de jaguar (a) y la coherencia de los grupos de mosaico (b) 

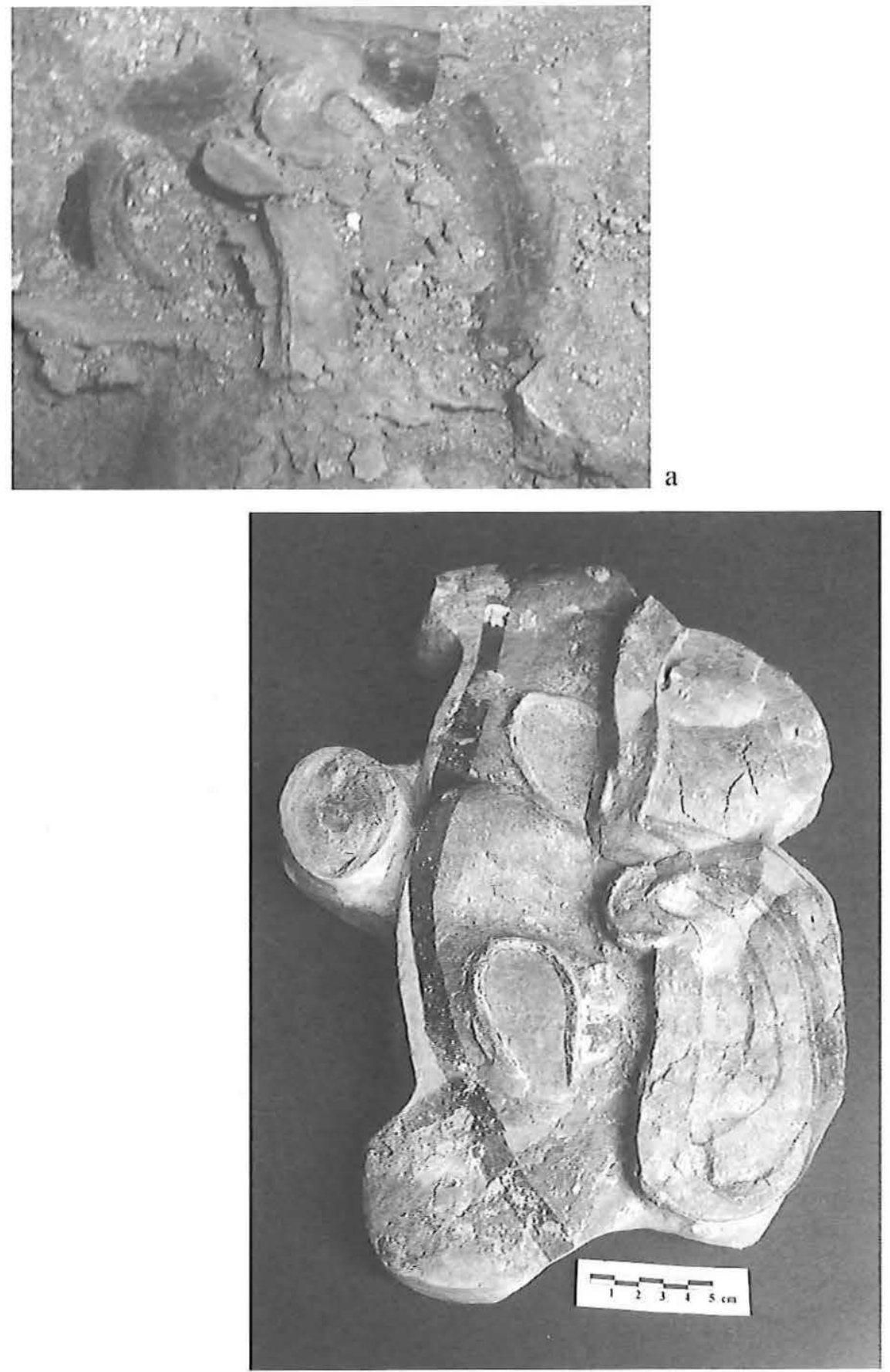

Fig. 3 - Vestigios del tocado de la tumba 6 in situ, en contacto con el cráneo de la acompañante (a) y el mismo después de su restauración (b) 


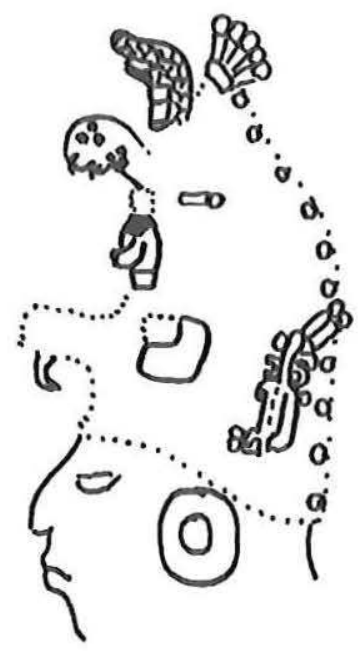

Fig. 4 - Esquema de la disposición de los elementos presentados en la Figura 5. Se observa en orden descendente el remate de concha nácar (g), la cabeza de serpiente (e), una "garra de jaguar " (Panthera onca), el torso humano sin rostro (c), los ojos en L (a), un colmillo (b); en el sector derecho se observa el perfil de la serpiente (d) y unos discos de nácar en el borde

proveyendo la unidad del tocado mediante un montaje museográfico adecuado. Este proyecto no ha sido concluído, por lo que se presenta aquí un esquema de la posición original de los elementos identificados, basado estrictamente en los datos arqueológicos, a diferencia de la reconstitución gráfica de la tumba 4 publicada anteriormente (García-Moreno y Granados 2000). Dejando a un lado las libertades de interpretación para lograr la unidad de la sepultura, se verá que los datos arqueológicos de los elementos conservados permanecen sin cambios (Figura 4). Los fragmentos han sido intervenidos mediante tratamientos mínimos de conservación y no han sido sometidos a una restauración. Ellos conservaban su volumen original en el momento del hallazgo, lo que permitió realizar un estudio iconográfico a partir de sus vestigios.

\section{Descripción iconográfica}

La decoración del tocado de la acompañante consiste en un relieve en estuco modelado, donde sobresale un elemento curvilíneo, de aspecto vegetal, que divide longitudinalmente el tocado en dos. Las secciones laterales fueron pintadas en verde y azul respectivamente. En el sector derecho del tocado se presenta un círculo rojo, ciertas áreas periféricas ocres y algunos volúmenes que fueron delineados en negro. Dos elementos ovalados fueron modelados en el centro. La 
forma de este tocado es bastante abstracta, aunque tiene un aspecto vegetal donde se percibe una intención de movimiento (Figura 3b).

El tocado del gobernante, por el contrario, presentaba una compleja decoración a base de figuras modeladas en estuco en alto relieve, logrando en ocasiones prácticamente esculturas en bulto exento. La parte frontal del tocado estaba recubierta por un mosaico de jadeita y concha, comparable a la mayoría de los tocados representados en estelas. La composición iconográfica de dicho tocado aparentemente representaría un mascarón con ojos en L, comparables a los de la deidad solar (Figuras 4 y 5a). Un par de colmillos de estuco rojo provendrían de sus fauces abiertas (Figuras 4 y 5 b). Los elementos centrales del tocado habrían sido dispuestos formando un eje vertical. Así, se sobrepondrían tres elementos esenciales en orden ascendente : un torso humano ataviado con un pectoral semicircular y un brazalete - su rostro no fue localizado - (Figuras 4 y 5c), los restos óseos de una pata de jaguar - huesos unguinales identificados como de Panthera onca - (Figura 2a) y una cabeza de serpiente elaborada en estuco con gran realismo (Figuras 4 y $5 \mathrm{e}$ ).

En distintos niveles fueron hallados 3 pares de prismas (Figura 5f), decorados con un disco de concha nácar en uno de sus extremos. Estos elementos fueron ampliamente representados en los tocados del área maya como elementos aislados o como obturadores asociados a las cabezas de serpientes. Este mismo tipo de discos nacarados aparecía en el remate superior del tocado (Figuras 4 y $5 \mathrm{~g}$ ) y en los bordes laterales del tocado, sistemáticamente dispuestos de manera equidistante (Figura 4). Estos elementos, presentes en los tocados de las estelas 17 y 43 de Calakmul y 11 de Yaxchilán, hacen pensar en representaciones asociadas al agua desde el tiempo de Chalcatzingo.

En el costado inferior izquierdo del tocado se ubicaba la representación abstracta de un perfil de serpiente (similar a los expuestos en las figuras 14 y 15 de Proskouriakoff 1950) en mosaico (Figuras 4 y $5 d$ ). Es posible que haya existido su contraparte en el lado derecho, como se observa en la mayoría de los tocados del Clásico. Sin embargo, esta zona presentaba un alto grado de alteración de los materiales.

\section{El ANÁLISIS DE LOS MATERIALES}

Los análisis preliminares fueron realizados en los laboratorios de la Subdirección de laboratorios y apoyo académico del INAH (SLAA) y en el Centre de recherche et restauration des musées de France (C2RMF). Estos se llevaron a cabo con el objetivo de conocer los materiales constitutivos de cada tocado y asimismo tener un acercamiento a las técnicas de manufactura empleadas. Las técnicas de examen y análisis fueron principalmente pruebas microquímicas, microscopía óptica y microscopía electrónica de barrido acoplado a un identifi- 


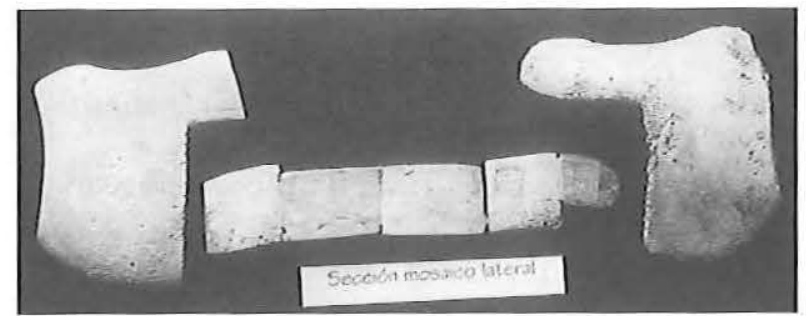

(a) Teselas en forma de ojos en L y alineamiento de algunas teselas de concha

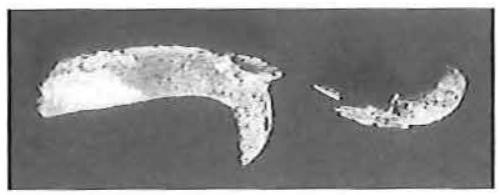

(b) Colmillos rojo en estuco

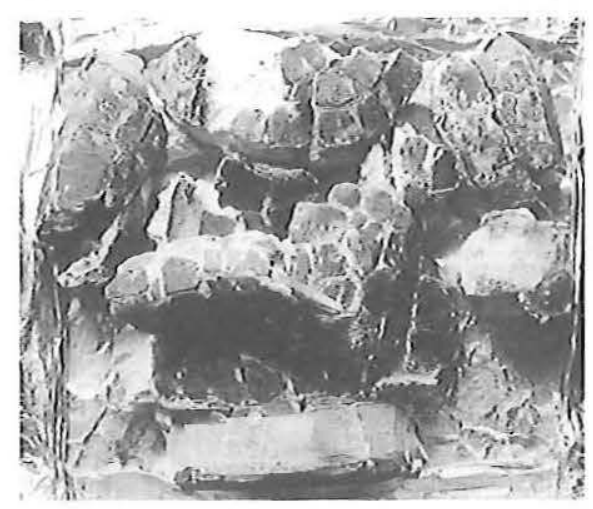

(c) Torso humano

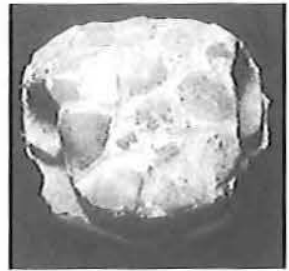

(e) Cabeza de serpiente

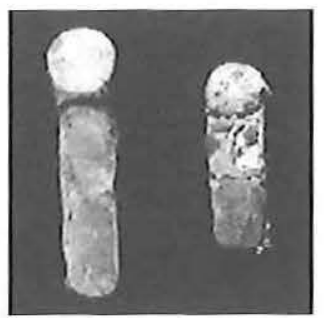

(f) Prismas con concha nácar

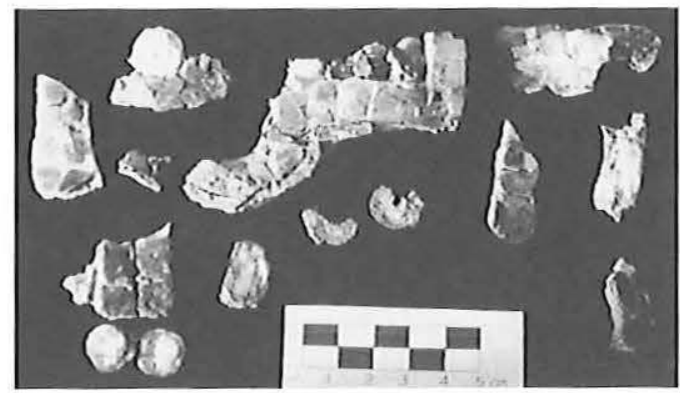

(d) Mosaico lateral representado un perfil abstracto de serpiente con colmillos en concha

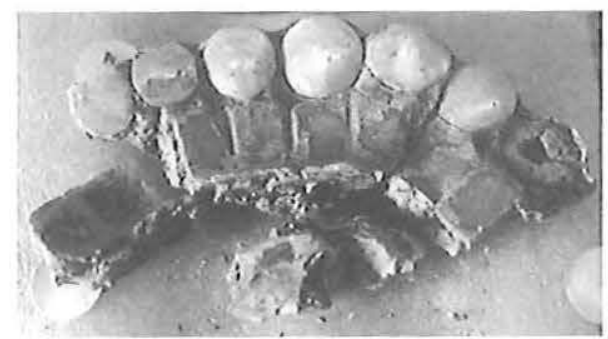

(g) Remate superior del tocado

Fig. 5 - Elementos del tocado de la tumba 4. Las letras designan su posición en la Figura 4 
cador elemental. Paralelamente, la espectrometría Raman y los análisis por PIXE fueron utilizados para la caracterización de las teselas de piedra verde.

El estudio material de los tocados incluyó la identificación de la materia orgánica fibrosa que componía el cuerpo o soporte de cada tocado. A pesar de su deterioro, ésta fue identificada por José Luis Alvarado y Fernando Sánchez Martínez (SLAA-INAH), como fibras de palma (García-Moreno y Granados 1999). Los haces de fibra fueron parcialmente conservados a pesar de su fragilidad por un proceso de mineralización, siendo la materia orgánica reemplazada por carbonatos de calcio y magnesio, como consecuencia de la aplicación de pastas de cal y del alto porcentaje de humedad relativa en la tumba. El grave deterioro de las fibras se tradujo en una falta de cohesión y debilitamiento de la estructura, lo cual dio lugar a la destrucción del tocado. En el caso del tocado del gobernante se localizaron restos de madera muy deteriorada al interior del soporte de palma, lo que indicaría la existencia de un eje vertical de refuerzo dentro del soporte de palma.

En el C2RMF se estudió principalmente la decoración de los tocados. Los análisis se enfocaron en las recetas de estuco y de la capa pictórica. Entre los resultados destaca la aplicación selectiva de diferentes pastas de estuco en los dos tocados. El tocado de la acompañante presenta un solo tipo de pasta de modelado a base de cal, mientras que el del dignatario presenta cinco tipos distintos de pastas con usos específicos. Un enlucido grueso, a base de una arcilla ferruginosa, fue usado únicamente como soporte de las teselas de concha. Tres variantes en los enlucidos a base de cal fueron diferenciados, según la composición, la granulometría de las cargas y la presencia de aglutinantes protéicos. Un último enlucido fue hecho a base de yeso.

En cuanto a las recetas de policromía, se comprobó la utilizacion de óxidos de hierro como pigmentos rojos y amarillos (posiblemente se trata de hematita y goethita respectivamente), así como de cinabrio, sulfuro de mercurio, de pureza variable para lograr un rojo intenso. El color verde se compone prioritariamente de carbonatos de cobre. El negro corresponde a negro de humo y hueso carbonizado. Con respecto al azul, la presencia de una arcilla indicaría que se trata de azul maya. Esta hipótesis se ve reforzada por una fuerte similitud con el espectro de referencia del indigo, mediante el análisis por espectrometría Raman. Esta última técnica y el método PIXE sirvieron paralelamente para identificar la piedra verde del mosaico como jadeita.

\section{Comentarios}

\section{Manufactura y uso}

Los análisis permitieron llevar a cabo una serie de observaciones sobre las técnicas de manufactura de ambos tocados. Las estructuras o soportes fueron 
hechas básicamente con atados de fibras de palma, unidos entre sí por un adhesivo de origen protéico y lechada de cal. El tocado del dignatario presentaba en el interior una espiga de madera que brindaba una mayor resistencia al tocado.

La utilización de la palma pudo presentar la ventaja de minimizar el peso de los tocados, que en ambos casos presentaban por lo menos $40 \mathrm{~cm}$ de altura por $25 \mathrm{~cm}$ de diámetro, dando como resultado la obtención de un bloque ligero, resistente y fácil de tallar. Hasta cierto punto podríamos comparar estos bloques iniciales con las esculturas de pasta de caña que, si bien de manera escasa, se siguen fabricando en México. Ambos tocados fueron posteriormente estucados, acentuando los volúmenes previamente tallados.

Las diferencias más notables entre los dos tocados se refieren a la composición formal y a los recursos técnicos empleados en su manufactura. La compleja decoración del tocado del gobernante, con materias mixtas e importante volumen de las esculturas, exige una gran destreza y un profundo conocimiento de los materiales. La elaboración de las diferentes pastas específicamente para el modelado, el soporte de mosaico o la superficie de pintura de acuerdo a sus cualidades plásticas, es tan sólo un ejemplo de la minucia con la que este objeto fue hecho.

Si bien la paleta cromática de los dos tocados es similar, vemos una mayor destreza en el uso de matices en el tocado del gobernante. Asimismo, el uso de cinabrio puro para pintar los colmillos en estuco contrasta con el uso prioritario de hematita en el tocado de la acompañante. La diferencia de materiales en la decoración de ambos tocados nos podría sugerir una codificación en la jerarquización de la indumentaria de la élite de Calakmul. Sin embargo, nuestro caso de estudio no es suficiente para ir más allá en este sentido.

Es posible constatar la importancia de la selección de materiales preciosos para la elaboración del tocado del dignatario. Así, la jadeita, el cinabrio y una pata de jaguar fueron utilizados realmente y no sólo representados con sus formas o colores. Los materiales utilizados son mayoritariamente exógenos a Calakmul. Si bien la palma pudo provenir de áreas cercanas, la concha, los pigmentos y la jadeita son productos que llegaron por intercambio de zonas lejanas. Sin embargo, los datos actuales no son suficientes para saber si los tocados fueron hechos en el sitio o si fueron importados.

Por la presente investigación se sugiere la existencia de una misma tradición en la manufactura de los tocados, compartida por otros sitios del Petén como Río Azul, Dos Pilas y Tikal. De acuerdo a los pocos vestigios arqueológicos presentes, parecería que la utilización de fibras de palma pudo ser una constante a nivel regional. El estudio comparativo de la policromía representa una vía indispensable para verificar esta hipótesis y, en general, para detectar las diferentes tradiciones pictóricas, como se ha propuesto para la pintura mural del área maya (de la Fuente y Staines 1998).

Las mayores diferencias de los tocados pueden obedecer igualmente a sus funciones y usos particulares. El tocado de la acompañante pudo haber sido 
elaborado para la ocasión del entierro, ya que su estado de conservación es relativamente bueno. Asimismo su sencillez formal y material podría explicarse si su elaboración formó parte de los preparativos del rito funerario del gobernante. A la inversa, la detallada manufactura del tocado del dignatario indica su posible uso en vida para algunas ceremonias, a pesar de que en las estelas del sitio aparecería portando otros tocados.

\section{Simbolismo}

A pesar de que el deterioro de las más de 100 estelas de Calakmul impide una comparación local detallada, es interesante constatar la presencia de motivos similares en el arte de la época. La organización política del área maya, basada en linajes (Martin y Grube 2000), pudo haber fortalecido una misma tradición de la vestimenta de élite entre las diferentes ciudades del Petén. Esta hipótesis se ve respaldada por la semejanza en las representaciones de la indumentaria de la élite maya, especialmente en los casos de Tikal, Calakmul y Yaxchilán. Sin embargo, podemos notar ciertas diferencias con respecto a Palenque o Copán (Baudez 1999).

En el Clásico Tardío se representaron ampliamente los tocados de tipo tambor o major-drum headdress (Tate 1992; Schele y Miller 1992). Se trata de estructuras cilíndricas, que soportan, en mayor o menor cantidad, diversos elementos con los que se componen complejos discursos simbólicos. Algunos de los motivos son recurrentes en los diferentes tocados, pero su disposición, tamaño y forma de representación adquieren valores únicos en cada caso. Así, es indudable que las innumerables asociaciones específicas de máscaras, figuras humanas, zoomorfas y geométricas estaban altamente codificadas. Asimismo, parece que los materiales pudieron haber sido seleccionados cuidadosamente para su fabricación, no sólo por sus cualidades prácticas y estéticas, sino por el valor simbólico asignado a la materia a través de su origen y/o de sus características físicas.

Particularmente la estela 9 de Calakmul, donde se presume figuran los padres del gobernante " Garra de Jaguar », comparte con este tocado varios aspectos iconográficos (Figura 6). La mujer representada porta un tocado en cuyo centro sobresale una cabeza de serpiente muy similar a la localizada como parte de los vestigios arqueológicos. Este elemento de aspecto naturalista podría ser un símbolo de la entidad políca o cuxcabal de la Cabeza de Serpiente.

Así, es posible que el discurso iconográfico del tocado se funde en la identidad misma del gobernante, al poseer al centro elementos con valor nominal tanto de su persona como del cuxcabal, entendiéndose por éstos la pata de jaguar y la cabeza del bífido, respectivamente. Es arriesgado interpretar si el torso humano alude al ahau mismo o bien a una deidad o ancestro protector del linaje. Aun así, el tocado parece ser el tercer objeto con el valor nominal del dignatario en la 

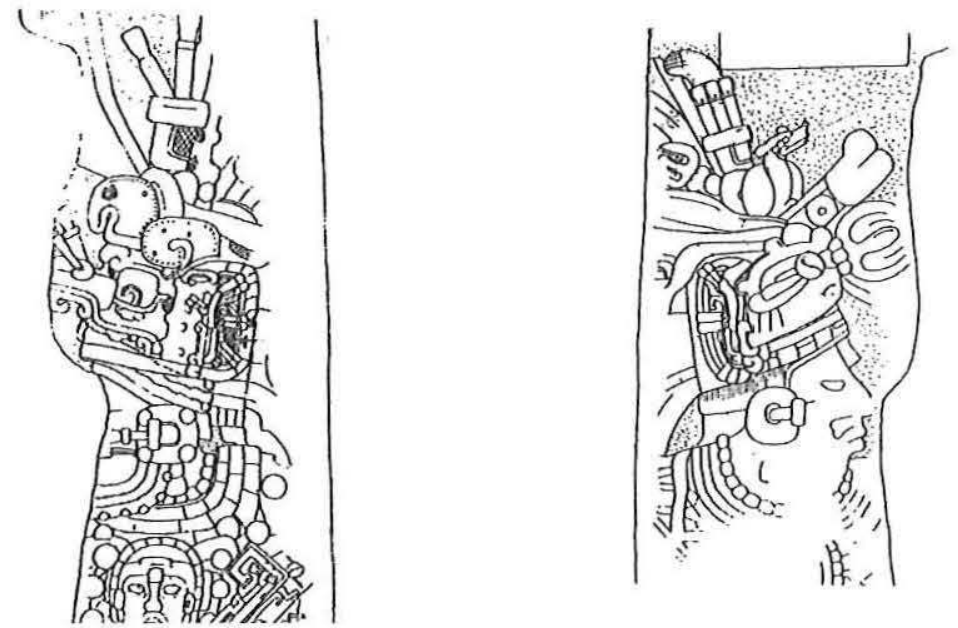

Fig. 6 - Detalles de la estela 9 de Calakmul donde se representa a los padres del gobernante (dibujado por Eric von Euw)

sepultura, junto con un plato que presenta el glifo "Garra de Jaguar » y la alusión al linaje Yuknom en la parte inferior de su máscara funeraria (Martin y Grube 2000).

La presente investigación no pretende ser concluyente ni exhaustiva, sino ofrecer un acercamiento lo más objetivo posible a dos tocados, como un ejemplo de las posibilidades que el material orgánico arqueológico puede presentar a pesar de su deterioro. Numerosas dudas sobre los tocados permanecen en pie. Futuros hallazgos podrían esclarecer datos sobre el lugar de producción de estos objetos y los límites geográficos de la tradición de la indumentaria. La existencia de un grupo de artesanos especializados en la elaboración de objetos de uso ritual ha sido sugerida por diferentes autores. Sin embargo, es gracias al análisis interdisciplinario de los vestigios arqueológicos que podremos obtener datos concretos, comparables a nivel regional, tanto en lo relativo a los materiales empleados como en el mensaje iconográfico.

Este trabajo fue posible gracias al PAC o Proyecto Arqueológico Calakmul del Instituto Nacional de Antropología e Historia, a la universidad de París I y al Centre de recherche et de restauration des musées de France, donde actualmente se lleva a cabo el estudio de las ofrendas funerarias de Calakmul, con el apoyo de CONACYT. 


\section{BIBLIOGRAFÍA}

Adams R.F.W.

1986 Rio Azul Reports, No.2, the 1984 season, Center for archaeological research, University of Texas, San Antonio.

Anawalt P. R.

1990 Indian clothing before Cortés : Mesoamerican costumes from the Codices, University of Oklahoma Press, Norman.

ARnoldi M. J. y C. Kreamer

1995 "Crowning achievements : African arts of dressing the head », African Arts (PAAR), 28 (I), pp. 22-35.

\section{Arqueología Mexicana}

1996 Indumentaria prehispánica, III (17), enero-febrero, ed. Raíces, México.

2000 Calakmul, la gran Urbe maya, VII (42), marzo-abril, ed. Raíces, México.

BAUDEZ C.-F.

1999 "Le roi maya en face», Journal de la Société des Américanistes, 85, pp. 43-64.

CARRASCO R., et al.

1999 Informe del proyecto arqueológico de Calakmul, temporada 1998-99, INAH-Campeche, México.

Carrasco R., S. Boucher, P. Alvarez, V. Tiesler, V. Garcia, R. García-Moreno y J. VAZQUEZ

1999 "A dynastic tomb from Campeche, Mexico. New Evidence on Jaguar Paw, a ruler of Calakmul ", Latin American Antiquity, 10 (1), pp. 47-58.

De La Fuente B. y L. Staines, eds

1998 La pintura mural prehispánica en México. Área maya Bonampa, IIEUNAM, México, vol. 2.

Demarest A., H. Escobedo, J. A. Valdés, S. Houston, L. Wright y K. Emery

1991 "Arqueología, epigrafía y el descubrimiento de una tumba real en el centro ceremonial de Dos Pilas, Petén, Guatemala », Utz'ib, Asociación Tikal, Guatemala, pp. 14-28.

Florian M. L., D. Kronkright y R. Norton, eds

1990 The conservation of artifacts made from plant materials, Paul Getty Trust, Princeton University Press, Princeton.

Garcia-Moreno R. y J. Granados

1999 La restauración de la joyería y la vestimenta fumeraria localizadas en la Tumba 4 de la Subestructura II-B de Calakmul, Campeche, ENCRM INAH, Tesis profesional, México.

2000 "Tumbas reales de Calakmul », Arqueología Mexicana, VII (42), marzoabril, Ed. Raíces, México, pp. 28-33. 


\section{Greene M.}

1997 Sixth palenque round table, Univesity of Oklahoma, Norman and London.

Hall G. D.

1989 Realm of death. Royal mortuary customs and polity interaction in the Classic Maya Lowlands, PhD Anthropology, Harvard University, Cambridge.

Helmuth N.

1967 Structure 5D-73, burial 196, Tikal, Peten, Guatemala : a preliminary report, Harvard College.

Houston S. y D. STUART

1998 "The ancient maya self, personhood and portraiture in the Classic Period ", R.E.S. Anthropology and Aesthetics, 33, pp. 73-101.

Martin S. y N. Grube

$2000 \quad$ Chronicle of the maya kings and queens. Deciphering the dynasties of the ancient Maya, Thames and Hudson, Londres.

ProskouriakofF T.

1950 A study of classic Maya sculpture, Carnegie Institution of Washington, Washington, D. C.

SCHELe L. y M. E. MiLLeR

1992 The blood of kings. Dynasty and ritual in maya art, Thames and Hudson, Londres.

SPINDEN H. J.

1913 A study of maya art : its subject matter and historical development, Harvard University, Cambridge, coll. « Memoirs of the Peabody Museum of Archaeology and Ethnology » 6.

STONE A.

1986 "Aspects of Impersonification in Classic Maya Art », in Greene M., Sixth Palenque Round Table, Univesity of Oklahoma, Norman and

TATE C.

1992 Yaxchilan. The design of maya ceremonial city, University of Texas Press, Austin.

Von Euw E.

[s. d.] Dibujos de las estelas de Calakmul, Manuscrito en posesión del INAHCampeche. 